Research Article

\title{
Technical Efficiency and Productivity Analysis of Bitter Gourd- Capsicum Multiple Cropping System under Tunnels in Punjab, Pakistan
}

\author{
Hina Fatima $^{1 *}$, Bushra Yasmin ${ }^{2}$ and Lal Khan Almas ${ }^{3}$ \\ ${ }^{1}$ Department of Economics, Mohammad Ali Jinnah University, Karachi, Pakistan; ${ }^{2}$ Department of Economics, Fatima Jinnah \\ Women University, Rawalpindi, Pakistan; ${ }^{3}$ Department of Agricultural Business and Economics West Texas A and M University, \\ Canyon, TX USA.
}

Abstract | This research focuses on the efficiency and productivity analysis of bitter gourd-capsicum multiple
cropping systems under tunnels in Punjab, Pakistan. Given the wide land fragmentation and high population
pressure, this is the dire need of time to get farmers involved in advanced and intensive farming techniques to
attain self-sufficiency in production. This study conducted the efficiency and productivity analysis by applying
the parametric and non-parametric techniques to evaluate the optimal utilization of farm resources in multiple
cropping system and the efficiency gains from tunnel technology. The data were collected from 150 multiple
bitter gourd-capsicum cropping system farms. The empirical findings yielded an average technical efficiency
of score 0.79 in bitter gourd-capsicum cropping systems. More intrinsically, the apparent output gap is due to
inefficient utilization of inputs within given farm resources that can be improved by proper farm management
practices, enhancing farmers' knowledge regarding inputs quality and its time-effective utilization in addition
to the marketing information about availability of innovative inputs. This is learned from the results that
multiple cropping under tunnels appeared as a cutting-edge system among the prevalent agricultural practices
in Pakistan that demands modernity and challenges on the part of farmers.
Received | May 08, 2020; Accepted | May 13, 2021; Published | October 01, 2021
"Correspondence | Hina Fatima, Department of Economics, Mohammad Ali Jinnah University, Karachi, Pakistan;
Email: Hina.fatima@jinnah.edu
Citation | Fatima, H., B. Yasmin and L.K. Almas.2021. Technical efficiency and productivity analysis of bitter gourd-capsicum multiple cropping
system under tunnels in Punjab, Pakistan. Sarbad Journal of Agriculture, 37(4): 1403-1417.
DOI | https://dx.doi.org/10.17582/journal.sja/2021/37.4.1403.1417,
Keywords | Tunnel farming, Multiple cropping systems, Technical efficiency, Data envelopment analysis, Stochastic frontier analysis

\section{Introduction}

$\mathrm{E}$ conomic development in the developing countries is critically reliant on the agricultural sector that is not possible without farm managers upgraded managerial abilities. Such abilities can be enhanced through firm training and formal and informal education of the farmers. Technical changes in the farm sector encourage the farm productivity due to parallel association with farm management and inputs. Technology adoption may also resolve the problem of food shortages, particularly in case of developing countries. The $21^{\text {st }}$ century requires another green revolution due to increasing scarcity of resources particularly including water and arable land. Advanced technology can be helpful to overcome these constraints and increasing farm output per hectare.

For the period of 70 years of independence, and despite adopting green revolution in 1960s that introduced high yielding seed varieties, chemical/ 
commercial fertilizers at large-scale and plant protection know-how, Pakistan is still unable to feed its population adequately. The accelerating population ultimately leads to the shortages of food, fiber and industrial crops that hampers the overall process of economic growth. According to GoP (2009-10), Pakistan will be the most populated country of the world by the end of 2050. Along this fast-pacing population growth, it is required to stepping up the farm sector of the country by introducing new production methods and technologies in the system. With the rising population and scarce water and land resources, food security has become a global issue. Hence, the diversion from traditional to hightech multiple cropping system is required for better utilization of available resources. Ultimately, the food security concerns can be addressed more profoundly.

Though the multiple cropping has been a conventional system in practice since the earliest ages of human development, it has been developed on better framework in modern times and is being practiced under tunnels as well. Mainly, two conspicuous cropping systems are existent in the tunnel farming system in Pakistan. One is multiple cropping system, and another is mono cropping system. Most of the crops grown under tunnels is horticultural crops. These horticultural crops include capsicum, bitter gourd, green chilies, melon, cucumber, bringle (eggplant), and tomato. The frequently grown multiple cropping combinations under the tunnels are capsicum and bitter gourd, cucumber and bitter gourd, cucumber and capsicum and cotton and melon.

Technical change in the farm sector boosts farm productivity due to the parallel association between farm management and inputs. Technological change in the farm sector is one of the finest modes for the improvement of farm yield. The major significance of this study is that very little research work has been done on the efficiency analysis of multiple cropping systems under tunnels in Pakistan. Presently, few studies are available that have descriptively analyzed the feasibility of a mono-cropping system under tunnels by taking the sample of few farmers. The contribution of the current study is that it has not only done the technical efficiency analysis of multiple cropping system but also evaluated the unbalanced application of farm inputs through benchmark analysis. This analysis guides the farmers that how important it is to apply the balanced inputs in order to attain the best possible output, minimum cost and high returns.

It is pertinent to mention that a limited number of studies have conducted the efficiency analysis of multiple cropping system at global level. Amos et al. (2004) estimated the technical efficiency of sole and mixed cropping patterns in Nigeria for the smallscale farmers. The study provided that mixed cropping pattern yields high returns to small scale farmers on the one hand, and simultaneous application of inputs on two crops results in lower cost of production compared to the sole crop cultivation, on the other. In another study for African region, (Mkhabela, 2005) examined the technical efficiency of mixed cropping system by selecting a diverse vegetable crops' combination that grow at the same time and space. The study concluded that crop diversification, use of new technologies and government positive interventions can support in enhancing the technical efficiency of mixed vegetable farming system. According to (Manyong et al., 2006), consistent adoption of improved agricultural technologies was found to be helpful in attaining an enhanced technical efficiency in the innovating intercropping system.

While studying the consequences of socioeconomic factors on technical efficiency of multiple cropping farms (Kolawole, 2009) pointed out that farmers' education, availability of credit and extension services delivers the highest level of technical efficiency scores in the multiple cropping farms. Hence, inclusive performance of multiple-cropping system, in terms of productivity and efficiency, is positively influenced by the above cited factors. (Beshir, 2011) by estimating the technical, allocative and economic efficiency of livestock and mixed cropping concluded that inefficiencies could be minimized by adoption of new technologies and raising the farmers'level of education. (Alene and Zeller, 2005) conducted the efficiency analysis of multiple cropping adopters of cereal production in Ethiopia by using distance functions and DEA. The result of the study demonstrated high technical inefficiencies in multiple cropping systems. Even the introduction of improved technologies and systems brought no sharp increase in cereal yields. The mismanagement in application of proper method due to lack of knowledge among the high technology adopters is the major factor behind such inadequate results for multiple cereals cropping system. 
According to Khan and Ali (2013), small-scale farming along with the introduction of high-tech technologies and rational policies will be beneficial in enhancing farm productivity and income. According to Bravo-Ureta and Pinheiro (1993) though in recent years, the application of high-tech inputs has already been increased but important is to use those farm technologies optimally and efficiently. To achieve high returns in the agriculture sector, it is needed that government should finance more towards farmers' formal and informal education. An educated farmer plausibly is able to increase farm production on an efficient production scale by improving the efficacy of farm inputs (Khan and Ali, 2013).

The full coverage of extension services and optimal application of improved technologies can help in bearing high productivity goals.

\section{Objectives of the study}

This study evaluates the efficiency of bitter gourdcapsicum crop combination for further analysis that whether it is helpful in increasing the productivity of available land by optimally utilizing farm resources. The study can be guideline for policy makers in increasing per unit area productivity in Pakistan by analyzing the prevalent negative gaps in farm practices under multiple-cropping system under tunnels.

\section{Materials and Methods}

To investigate the efficiency level of targeted farmers of multiple cropping systems under tunnels crosssectional primary survey was conducted. The data for current study have been collected with the help of a questionnaire during the year 2014-2015. At the time of data collection around 1000 farmers were engaged in planting the crops under tunnels. Out of 1000 farmers around 200 farmers were cultivating the bitter gourd-capsicum cropping system combination under tunnels. The sampled cities for bitter gourd-capsicum combination include Faisalabad (12), Mureedwala (4), Sumundri (24), Tandlianwala (26) TobaTek Singh (15), Gojra (17), Kamalia (12) and Mamu Kanjan (38), with respective number of farmers in parentheses. The crop combination selected for the present study is capsicum and bitter gourd cropping system under tunnels and the information was gathered from 150 farms from the Faisalabad division.

With the background of standard production function, the production frontier is an extension of traditional regression model of the production function. In the context of this study, the aim is to evaluate how to magnify the efficiency and productivity of bitter gourd-capsicum multiple cropping system in Pakistan. Two major techniques are generally employed to measure the productivity and efficiency analysis of the agricultural sector, namely, Stochastic Frontier Approach (SFA) and Data Envelopment Approach (DEA). The SFA is a parametric technique and is based on regression analysis, among output and inputs. DEA is a non-parametric approach and originated from mathematical programming of linear piecewise functions. This study employs the parametric and non-parametric methods both in order to secure the robust efficiency analysis.

Efficiency is about the relative performance of an economic unit regarding the conversion of inputs into outputs, associated with a standard. According to (Farrell, 1957), efficiency is defined as the actual productivity of a firm relative to its maximal productivity where maximal productivity is well-defined by the production frontier. A comprehensive literature is available on the frontier production including (Forsund et al., 1980; Jondrow et al., 1982; Kalirajan and Flinn, 1983; Battese and Coelli, 1988; Kalirajan, 1991; Coelli, 1996; Greene, 2007).

\section{Stochastic frontier analysis (SFA)}

The production frontier model has been extended by several researchers including (Farrell and Fieldhouse,1962; Aigner et al., 1977; Battese and Corra, 1977; Meeusen and Van den Broeck, 1977; Lee and Tyler, 1978; Pitt and Lee, 1981; Kalirajan and Flinn, 1983; Schmidt and Sickles,1984; Battese and Coelli, 1988) who incorporated the factors from inside and outside of farmer's control, gradually.

The production function typically written as:

$$
Y=f\left(x_{1}, x_{2}, \ldots, x_{N}\right)+v
$$

The standard production function shows the relationship between output and a given set of inputs and assumes that all the farms are efficient and there is no data noise. The production function of SFA is given as:

$$
Y=f\left(x_{1}+x_{2}, \ldots, x_{N}\right)+v-u
$$

The econometric model of SFA is generally written as:

$$
Y_{i}=f\left(\beta x_{i}+v_{i}-u_{i}\right)
$$


In SFA production function, the major indication is to decompose the stochastic part in two components. The Equation 3 highlights that actual production is now less than what is defined by the general production function. For estimation of the unknown parameter Maximum Likelihood Estimation (MLE) methods are used (Coelli, 1995). It is necessary to make standard assumptions for stochastic frontier model estimation of the distribution of variance parameters, such as $v_{i}$ and $u_{i}$.

Where, $v_{i}$ is the symmetric error term (noise), identically and independently distributed with zero mean and variance $v_{i} \sim N\left(0, \sigma_{v}{ }^{2}\right)$ i.e., normal distribution. Similarly, $u_{i}$ is a non-negative inefficiency error term and assumes only positive values, is identically and independently distributed with zero mean and variance $\left.u_{i} \sim N\left(0, \sigma_{u}^{2}\right)\right)$, i.e., half normal distribution (Neff et al., 1993).

The variance parameters $\left(u_{i}\right.$ and $\left.v_{i}\right)$ in Stochastic frontier are re-parameterized in following procedures are given by (Battese and Corra, 1977). After the estimation of stochastic frontier model, we procured the following form of unknown parameters.

$$
\begin{gathered}
\sigma^{2}=\sigma_{v}{ }^{2}+\sigma_{u}{ }^{2} \\
\gamma=\frac{\sigma_{v}^{2}}{\sigma_{u}^{2}}
\end{gathered}
$$

The value of $\gamma$ remains between zero and one. Hence, if the value of $\gamma$ equals zero, it indicates that difference between farms'output is due to random error and if $\gamma$ is equals to one it means that entire variation in farms output is due to technical inefficiency (Battese and Corra, 1977; Coelli, 1995).

A general form to measure technical efficiency of production frontier can be written as:

$$
T \cdot E F_{i}=\frac{y_{i}}{\exp \left(x_{i} \beta\right)}=\exp \left(-u_{i}\right)
$$

Where T.EF the technical efficiency of $\mathrm{i}^{\text {th }}$ farm and $\exp \left(-u_{i}\right)$ is the conditional exponential composite error term based on the case of half normal distribution, suggested by Battese and Coelli (1995).

In the present study, the Cobb-Douglas functional form is considered as a standard form of the bitter gourd-capsicum production function.

$$
\ln y_{i}=\beta_{o}+\beta_{i} \ln x_{i}+v_{i}-u_{i}
$$

The justification of the variables takes into account the bitter-gourd production function model as follows: $Y_{i}$ of the bitter gourd and capsicum output has been put up with using the quantity index. Where the quantity index is given by:

$$
\begin{aligned}
& Y_{i k}=\sum_{k=1}^{J} W_{i k} X_{i k} \\
& i=(1,2,3 \ldots, 150), \quad K=\left(K_{1}, K_{2}\right)
\end{aligned}
$$

$\mathrm{K}=$ Capsicum-Bitter gourd multiple cropping, Where, $\mathrm{W}$ is the weight given to the quantity of each $\mathrm{K}_{1}$ and $\mathrm{K}_{2}$ crops over the $\mathrm{i}^{\text {th }}$ farm and is given by:

$W=$ weightof the $K_{\text {th }}$ crop $=$ Outputf $K_{1}$ crop $/\left[\left\{\right.\right.$ totalvalueof $K_{1}$ and $K_{2}$ crop $\left.\}\right]$

The quantity indexes have been developed for $\mathrm{K}$ combination of crops under the multiple cropping. The output of each crop is taken in kilograms. This index has been developed for having a combined quantity of bitter gourd and capsicum crop produced per acre in the multiple cropping system. The description of the independent variables of production models is as follows: Where $i=1,2, \ldots, 150$ farms, $y_{i}$ is the qunitiy index of bitter gourd-capsicum crops, $x_{i}$ is the matrix for selected explanatory variables and include $X_{1}$, total number of labor hours/acre, $X_{2}$, NPK Nutrients/ acre $\mathrm{N}=$ Nitrogen, $\mathrm{P}=$ Potash= Phosphorus are the nutrients that are used by the farmers for multiple crops production process, $X_{3}$, total number of irrigation/acre, $X_{4}$, number of pesticide spray/acre, $X_{5}$, total number of hours for land preparation/acre (ploughing, planking, hewing, land leveling, broadcasting), $X_{6}$, seed rate of bitter gourd crop (grams)/acre and $X_{7}$ seed rate of the capsicum crop (grams)/acre.

The stochastic frontier model can be estimated by a two-stage method where the stochastic frontier is obtained at first and then the predicted efficiencies are regressed on the selected socioeconomic and management factors (Battese and Coelli, 1995).

Following (Bravo-Ureta et al., 1993; Bravo-Ureta and Pinheiro, 1993; Ahmad et al., 2002; Abedullah et al., 2007). Current study used the functional form 
of inefficiency model defined by (Battese and Coelli, 1993, 1995) as follows:

$$
U_{i}=\delta_{0}+\sum_{j=1}^{9} \delta_{j} Z_{j}+W_{i}
$$

Where, $U_{i}$ denotes the technical inefficiency of bitter gourd-capsicum production system and $\delta_{j}$ are unknown parameters to be estimated, $Z_{i}$ represent the socio-economic, farm specific and management factors such as $Z_{1}$, age of farmer, $Z_{2}$, education of farm manager in years, $Z_{3}$, used as dummy variable; if farmer is 'tenant' under his/her cultivation $=1$ and ' 0 ' otherwise, $Z_{4}$, used as dummy variable, where if farmer is 'owner cum tenant'= 1 and ' 0 ' otherwise, $Z_{5}$, shows the farm distance from main market in kilometers $(\mathrm{Km}), Z_{6}$, represents the farmers access to credit used as dummy variable, if farmer has access to farm credit i.e., yes $=1$ and ' 0 ' otherwise, $Z_{7}$, represents the tractor ownership, used as dummy variable, if the farmer is 'owner of the tractor' $=1$ and ' 0 ' otherwise, $Z_{8}$, represents the operational holding under bitter gourd-capsicum cropping system and $Z_{9}$, represents the number of tunnels per acre under bitter gourdcapsicum cropping system.

\section{Data envelopment analysis (DEA)}

This study has adopted output-oriented variable returns to scale model to estimate the output that can be raised at given level of inputs in multiple cropping system under the tunnels' technology. Keeping in view the problems of above-mentioned model (Bankers et al., 1984) modified the constant returns to scale DEA model into a variable return to scale model by adding convexity constraints (Coelli et al.,1998).

$$
\begin{aligned}
& \operatorname{Max}_{\phi, \lambda} \phi \\
& \text { St } \\
& -\phi y_{i}+Y \lambda \geq 0, \\
& x i-X \lambda \geq 0, \\
& I 1 \lambda=1, \\
& \lambda \geq 0,
\end{aligned}
$$

Where, $I 1 \lambda=1$ represents a convexity constraint which ensures that an inefficient farm is only benchmarked against farms of a similar size. Here, $1 \leq \phi<\infty$ and the proportional rise in outputs attainable for the $i$-th firm, keeping quantities of input constant, is depicted by $\phi^{-1}$. Scores of the technical efficiency defined by $1 /$ $\phi$ ranges between zero and one.
The maximum likelihood estimates of the preferred bitter gourd-capsicum production frontier model will be obtained after testing various null hypotheses in order to assess aptness and consequences of the adopted model. The statistic related to this test is defined as:

$$
\lambda=-2 \ln \left[L\left(H_{0}\right) / L\left(H_{1}\right)\right]
$$

Where; $\mathrm{L}\left(\mathrm{H}_{1}\right)$ and $\mathrm{L}\left(\mathrm{H}_{0}\right)$ are the log-likelihood values of bitter gourd-capsicum adopted production model and of the restricted model specified by the formulated null hypothesis, respectively.

\section{Results and Discussion}

A number of skills are required to manage the farm in an efficient manner. These skills may not be acquired through informal learning process or may not be inherently present in the farmers. But these skills can be included in the formal learning and teaching process and can be demonstrated to the farmers. The process of demographic transition is in progress in Pakistan and the proportion of youth is highest in the total population. In labor-intensive developing countries, the strength, power and zeal are embodied in the farmers and is reflected in their practices, decrease after certain years of age and are replaced by conservatives and low level of production (Shumet, 2011).

Table 1 presents the descriptive statistics on major variables and suggest that this innovative and exploratory sort of farming practice i.e., multiple cropping under tunnel farming is commenced in Pakistan by the farmers having an average age of 41 in bitter gourd-capsicum cropping system under tunnels.

Farm management requires better education as it is pivotal in the selection of inputs and farm practices. Educated farmers can access and avail farm related information relevant to the type and timing of crops, efficient input adoption and consequently higher production (Askal, 2010). Educational attainment also varies across the sampled farmers. It has been observed that tunnel adapters are those farmers who have better education. On average the tunnels farmers have around 9 years of schooling in the study area. Consequently, in Punjab where $56 \%$ of the population of country reside and over 3.8 million people cannot read and write, the average of the middle level of 
education gives a very optimistic picture for the rural agricultural practices under tunnels. In the bitter gourd-capsicum cropping system, the average tunnel farming experience is around 5 to 6 years. Farm practice with a highly developed and skill demanding technology does require handy experience.

Table 1: Descriptive statistics.

$\begin{array}{lll}\text { Farm characteristics } & \text { Average } & \text { St. dev } \\ \text { Variable } & 41 & 9.17 \\ \text { Age } & 8.33 & 3.47 \\ \text { Education } & 5.30 & 2.66 \\ \text { Tunnel Farming Experience } & 4.85 & 3.38 \\ \text { Operational Holding } & & \\ \text { Farm Management Practices per acre } & 19.70 & 4.78 \\ \text { Land Preparation Days } & 3.86 & 0.98 \\ \text { Land Preparation Hours } & 35.67 & 6.39 \\ \text { Total Number of Irrigation } & 1890 & 270.9 \\ \text { Bitter gourd Seed Application } & 325.33 & 47.01 \\ \text { Capsicum Seed Application } & 5.28 & 1.97 \\ \text { Urea (Bags) } & 7.82 & 2.19 \\ \text { DAP (Bags) } & 4.43 & 2.18 \\ \text { SOP (Bags) } & 24.58 & 5.55 \\ \text { Pesticide Spray } & 16939.17 & 55280.76 \\ \text { Bitter gourd and Capsicum Output } & \text { Kg) per acre } \\ \text { Bitter gourd } & 27651 & 10540.04 \\ \text { Capsicum } & & \end{array}$

According to the Agricultural Census of Pakistan (GoP, 2010), average farm size in Pakistan is approximately 6.4 acres. Comparatively, the operational holding of current research is lower within an average of 4.8 approximately in the multiple cropping systems. Historically, the share of vegetable crop area under cultivation has remained low in Pakistan as compared to the share of area of major under cultivation.

Secondly, Table 1 reports the farm management practices in bitter gourd-capsicum cropping system. The land preparation activities that are generally carried out under tunnels includes deep plowing, leveling, bed-shedding, use of rotavator and cultivator, and plowing and planking. Land preparation for bitter gourd-capsicum requires a greater number of tools and time. In the study area, around 19 to 20 days' farmers expend for land preparation activities. During land preparation process for bitter gourdcapsicum cropping system, farmers daily spend around 3 to 4 hours, specific to land preparation practices. It appears that in the case of vegetable crops, land preparation practices are a bit analogous in the study area.

The Irrigation is considered as one of the most important inputs and asset as well especially during inadequate rainfalls. The timely availability of water is vital to the growth of the crop. It also makes the employment of high yielding varieties very easy (Datar and Delcarpio, 2009). The farmers of the bitter gourd-capsicum cropping system not only depend on the canal water but also on the tube well irrigation. The total number of irrigations applied by the farmers to the bitter gourd-capsicum cropping systems is around 35 to 36 .

The appropriate level of seeds application in multiple cropping systems under tunnels is vital for the plant growth as a specific quantity of seeds is required by each tunnel. Manual sowing is practiced in multiple cropping under tunnels, across the sampled area. In case of capsicum crop, on average farmer plants around 325 grams $(\mathrm{g})$ of capsicum seed per acre. In case of bitter gourd seed, farmers sow on average around 1890 grams (grams) seed per acre. In case of fertilizer application, the most frequent and extensive used is nitrogen nutrient in the study area, followed by phosphate and potassium. The uptake of plants might be improved if farmers' application of fertilizer is balanced.

The plant protection spray is decisive in preventing vegetables from the attack of pest, insect, weed, and fungus, etc. The quantity and the type of the spray are crucial in preventing any pest diseases. In sampled area, on average farmers applied a total number of pesticide spray around 24 to 25 times. It has been observed that the farmers haphazardly use pesticide spray for controlling the pest due to deficient knowledge. Such practices subsequently result in the increase in cost of production significantly compromising the benefits to the farmers.

In the study area, bitter gourd and capsicum crops are grown together under the tunnels due to same environmental demand. In bitter gourd-capsicum cropping system the average yield of capsicum crop cultivated with the bitter gourd crop is around 16939 $\mathrm{kg}$. On the other hand, the average yield of bitter gourd is around $27651 \mathrm{~kg}$ per acre. These figures clearly indicate that in the study area farmers can reap abundant farm output when both crops are grown in combination. 
Table 2 shows the result of the likelihood ratio test for bitter gourd-capsicum production model to evaluate the aptness and consequences of the adopted model.

Table 2: Hypothesis testing for bitter gourd-capsicum stochastic frontier production.

\begin{tabular}{|c|c|c|c|c|}
\hline Hypothesis & $\begin{array}{l}\text { Log like- } \\
\text { lihood } \\
\text { value }\end{array}$ & $\begin{array}{l}\text { Test sta- } \\
\text { tistics } \\
\text { value }\end{array}$ & $\begin{array}{l}\text { Critical } \\
\text { value } x^{2} \\
0.05\end{array}$ & Decision \\
\hline \multicolumn{5}{|c|}{$\mathrm{H}_{0}: \gamma=\delta_{0}=\delta_{1}=\delta_{2}=\delta_{3} \ldots \ldots \delta_{9}=0$} \\
\hline $\begin{array}{l}\text { Bitter gourd- } \\
\text { capsicum } \\
\text { cropping system }\end{array}$ & -30.7 & 113.98 & $5.14-19.04$ & Rejected \\
\hline \multicolumn{5}{|c|}{$\mathrm{H}_{0}: \delta_{0}=\delta_{1}=\delta_{2}=\delta_{3} \ldots \ldots \delta_{9}=0$} \\
\hline $\begin{array}{l}\text { Bitter gourd- } \\
\text { capsicum } \\
\text { cropping system }\end{array}$ & -43.3 & 138.8 & 18.31 & Rejected \\
\hline
\end{tabular}

The first hypothesis for bitter gourd-capsicum cropping system stated that there is no technical inefficiency effect present in bitter Gourd and capsicum cropping system. Here, the stochastic frontier analysis and Ordinary Least Square (OLS) techniques are applied and the log likelihood values of stochastic frontier analysis and OLS bitter gourdcapsicum production models are found -30.7 . The calculated value of LR test statistics is 113.98 , which is higher than the tabulated value of Chi-square at 5 percent level of significance, which is $5.14-19.04$. The result from first null hypothesis test advocated that Ordinary Least Square (OLS) technique is not suitable for the sample data of bitter gourd and Capsicum cropping system.

Similarly, the second null hypothesis is specified as that socioeconomic and farm specific management factors have no influence on technical efficiency. The results obtained from the LR test rejected the null hypothesis in favor of the alternative hypothesis. The calculated value acquired from LR test is greater than the Chi square tabulated value, which is 18.30 . This result implies that socioeconomic and farm specific management factors have substantial influence on the technical efficiency of bitter-gourd-capsicum cropping system growers.

Next, the maximum-likelihood estimates (MLE) of the parameters of Cobb-Douglas stochastic frontier function are obtained using maximum-likelihood procedures, by using FRONTIER 4.1 (Coelli, 1996).

The results given in Table 3 shows the bitter gourdcapsicum production frontier analysis. The crop seed are important input factor and determinant of farm production and productivity. The coefficient of capsicum seed rate carries negative sign, but it is insignificant. The coefficient of bitter gourd seed is positive and significant.

The Table 3 reports the results of bitter gourdcapsicum production frontier analysis. The crop seed is an important input factor and major determinant of farm production as well as productivity. The earlier studies display the varied effect of seed expenditures on farm efficiency. Such results had also been reported by Okoboi (2010). According to that study, costs on seed had insignificant impact on farm efficiency.In current study, the coefficient of capsicum seed rate has a negative sign, but it is insignificant. The coefficient of bitter gourd seed is positive and significant. The result reports that in the case of multiple cropping, most of the farmers use the unbalanced seed rate.

Table 3: Bitter gourd-capsicum stochastic frontier.

\begin{tabular}{llllllll} 
Variables & & OLS & & \multicolumn{1}{c}{ MLE } \\
Intercept & Parameters & Coefficients & Std-err & t-ratio & Coefficients & Std-err & t-ratio \\
Capsicum seed & $\beta_{0}$ & 0.529 & 1.461 & 0.362 & $0.065^{* * * *}$ & 0.647 & 10.05 \\
Bitter gourd seed & $\beta_{1}$ & -0.217 & 0.150 & -1.451 & -0.037 & 0.074 & -0.49 \\
Total no. Irrigations & $\beta_{2}$ & $0.798^{* * *}$ & 0.199 & 4.011 & $0.164^{* *}$ & 0.072 & 2.27 \\
Pesticide & $\beta_{3}$ & 0.022 & 0.156 & 0.143 & $0.167^{*}$ & 0.091 & 1.83 \\
NPK & $\beta_{4}$ & -0.155 & 0.110 & -1.402 & -0.004 & 0.049 & -0.09 \\
Labor hours & $\beta_{5}$ & $0.151^{*}$ & 0.793 & 1.910 & $0.069^{* *}$ & 0.033 & 2.07 \\
Land Preparation hours & $\beta_{6}$ & $0.761^{* * *}$ & 0.152 & 4.977 & $0.416^{* * *}$ & 0.082 & 5.06 \\
Sigma-Squared & $\beta_{7}$ & $0.678^{* * *}$ & 0.150 & 4.517 & $0.236^{* * *}$ & 0.071 & 3.33 \\
Gamma & & 0.093 & & & 0.786 & &
\end{tabular}

*:10\% significance; **: $5 \%$ significance; ${ }^{*}:$ : $1 \%$ significance. 
As far as vegetables are concerned in multiple cropping under tunnels, accurate quantity of seed should be sown. This is not the case with the multiple crop combination of bitter gourd-capsicum under tunnels where seeds are sown in an arbitrary amount, quite peculiar in case of capsicum crop. It is needed that farmers should realize that quality of seed matters more than quantity of seed, especially when crops are cultivated under tunnels. Hence, to meet higher level of crop productivity, farmers should be provided high quality of seed, which live up to local conditions and environment. The supply of higher quality of seed may fulfill farmers' demand if public and private sectors are geared up together. The improved vegetable seed varieties can provide the highest level of crop yield per acre. Accessibility to improved seed technology and reduction in prices can act as incentives to adopt improved technology.

The coefficient of total number of irrigations is positive and has significant impact on bitter gourd and capsicum productivity. This result implies that proper and timely application of irrigations to the multiple crops under tunnels is essential to enhance the bitter gourd and capsicum production. According to Ahmad et al. (2002), Abedullah (2006), Suresh and Reddy (2006), Hussain (2012), Hasnain (2015) and Fatima and Khan (2015), well-timed and wellorganized application of irrigation results in higher crop production.

The coefficient of pesticide spray is negative, but it is insignificant. This result indicates that there is unbalanced application of pesticide spray in study area. However, the coefficient for pesticide spray is insignificant which highlights the fact that pesticides must be cautiously used on pest or diseased parts to avoid crop output decline because of harmful effects of pest related to the crops. The agricultural research related organizations should guide and recommend farmers to follow integrated pest management. Conversely, Tella (2006), by using Timmer and Kopp indices, disclosed that if chemicals are not correctly utilized, productivity can be negatively affected.

The variable of NPK has turned out to be positive and highly significant in relation to bitter gourd-capsicum produces, implying that balanced amount and highquality of fertilizers should be used for increasing level of output. The earlier studies of Hussain (1995), Ahmad and Ahmad (1998), Ahmad et al. (2002),
Hassaan and Ahmad (2005), Saeed and Khan (2007), Sadiq et al. (2009) and Fatima and Khan (2015) by using stochastic frontier model, observed that the use of fertilizer increased the productivity of crops in Pakistan. Balanced application of fertilizer accordance to the soil quality and crop requirement would improve the plant uptake and crop production.

The labor input is one of the most crucial inputs in tunnel farming. This farming quite depends on efficient utilization of labor input. In this study, the coefficient of labor hour is positive and significant. The findings of present study are also supported by earlier studies including, (Abedullah et al., 2006; Ali et al., 2013; Saddozai et al., 2013). In study area, farm managers in every cropping season of tunnel farming prefer to hire those labors that previously worked on tunnel farms and have the experience of tunnel technology. Hence, those labors have skills and sound knowledge of tunnel farming. Therefore, present result reported that efficient and skillful labor is an exhortative factor for adoption of high-yielding multiple cropping systems under tunnel technology.

Land preparation is one of the most initial steps of crop management practices. The coefficient of land preparation hour is positive and significant. The result implies that to exploit the true potential of other inputs such as seed rate, fertilizer application and irrigation etc., it is essential to spend substantial time in land preparation practices that will ultimately culminate in higher farm productivity. Crop productivity can be manifold through timely and better application of land preparation activities, irrigations, improved seed beds, and weed control.

The major reasons that generally cause the inconsistency in output of bitter gourd-capsicum cropping system, is difference in timings of application of inputs, farmers handling attitude towards pests' attack, farm management and availability of financial resources on time. All these factors together affect the production of bitter gourd-capsicum cropping system. The Maximum Likelihood Estimation (MLE) of inefficiency effect offers the description of socioeconomic, management and farm specific factors that influence the technical efficiency and are reported in Table 4.

In the present study, the result of technical inefficiency model of bitter gourd-capsicum cropping system 
shows an inverse, but insignificant relationship between the age of farmer and the technical efficiency of bitter gourd-capsicum cropping system. This result has a plausible explanation of the decrease in technical inefficiency of bitter gourd-capsicum farms to increase with age, but it is insignificant.

Table 4: Bitter gourd-capsicum technical inefficiency model.

\begin{tabular}{|c|c|c|c|c|}
\hline Variables & $\begin{array}{l}\text { Parame- } \\
\text { ters }\end{array}$ & $\begin{array}{l}\text { Coeffi- } \\
\text { cients }\end{array}$ & Std-err & t-ratio \\
\hline Age of Farmer & $\delta 1$ & -0.004 & 0.010 & -0.41 \\
\hline Education & $\delta 2$ & $-0.259^{* * *}$ & 0.056 & -4.57 \\
\hline $\begin{array}{l}\text { Distance from main } \\
\text { Market }\end{array}$ & $\delta 3$ & $0.013^{* *}$ & 0.005 & 2.52 \\
\hline Tractor Ownership & $\delta 4$ & 0.099 & 0.226 & 0.44 \\
\hline Tenant & $\delta 5$ & $0.778^{* * *}$ & 0.276 & 2.81 \\
\hline Own-cum Tenant & $\delta 6$ & -0.097 & 0.330 & -0.29 \\
\hline Credit Sources & $\delta 7$ & $-0.570^{* *}$ & 0.275 & -2.07 \\
\hline Operational Holding & $\delta 8$ & $-0.231^{* * *}$ & 0.036 & -6.25 \\
\hline No. of Tunnels & $\delta 9$ & 0.011 & 0.038 & 0.299 \\
\hline
\end{tabular}

The coefficient of education is negative and significant, showing that farmers' education can bring improvement in technical efficiency of bitter gourd-capsicum farms. Literate farmers have the inclination towards adoption and the better use of technology. The distance of the farm from main market is inversely related to the technical efficiency. Average farm distance from the main market of Faisalabad is around 60 kilometers $(\mathrm{Km})$. Generally, larger farm distance from the main market results in higher transportation cost, and have more chances of crop damage, especially in case of vegetable crops. Ahmad et al. (2002) also found that the farm distance from main market contributes negatively to the farm technical efficiency.

The variable of tractor ownership used as dummy variable, where value of 1 indicates that the tractor is owned by the farmer and zero otherwise. This variable has a positive and significant coefficient identifying that the technical inefficiency of bitter gourdcapsicum farmers increases if tractor is owned by the farmer. This negative relationship with technical efficiency has the plausible explanation. The farmers in the study area who owned the tractors are used to give their tractors on rent and disburse more time for land preparation activities for the other farmers to increase their earrings also in the form of tractor's rent. This situation may justify the increase in technical inefficiency of bitter gourd-capsicum farms.

The tenancy status includes the variables such as tenant, owner cum tenant and farm owner. Where farm owner variable is used as the base category. The results show that owner cum tenant variable is insignificant. In case of a tenant, the result revealed positive and significant coefficient implying that tenants are more inefficient than the owner of lands. This result is quite logical because compared to the tenant, farmers who own land are mostly ready to make huge investment and have the tendency to adopt new farm technologies for their land. This attitude alternatively resulted in higher level of farm efficiency.

The result of study reveals that the coefficient of access to credit has inverse and significant relationship with technical inefficiency. It is evident that having access to credit facilities, contributes positively to the technical efficiency of bitter gourd-capsicum cropping system. According to Obwona (2000), it is found that access to credit facilities has the enhancement effect on the efficiency among farm managers. Hence, the access to credit facilities is a vital factor for farm technical efficiency.

The result of operational holding shows the inverse relationship with technical inefficiency. As the operational holding for bitter gourd-capsicum multiple cropping system under tunnels increases the technical inefficiency diminishes. The coefficient of the number of tunnels (as measured by the number of tunnels per acre) has a negative and significant impact on the technical inefficiency. In case of bitter gourd-capsicum multiple cropping system, under tunnels, the technical efficiency of farms increases as the number of tunnels increase. Hence, it is advisable to put up an optimum number of tunnels in bitter gourd-capsicum cropping system.

Table 5 shows the results of return to scale of bitter gourd-capsicum cropping system.

The calculation of return to scale in Cobb-Douglas production function is done by summing up the coefficients of bitter gourd-capsicum production function of $\beta$ parameters. The value of return of scale (1.013) shows that the bitter gourd-Capsicum 
farmers are experiencing the constant return to scale in production. Alternately, the bitter gourd-capsicum cropping system is on the boundaries of stage II production function. So, it is prudent for the farmers to optimally utilize the given level of inputs in order to attain the maximum level of output. Adding up the inputs will be resulted in the wastage of resources and increase in the cost of production.

Table 5: Returns to scale of bitter gourd-capsicum cropping system.

$\begin{array}{lll}\text { Variables } & \text { Parameters } & \text { Coefficients } \\ \text { Capsicum seed } & \beta_{1} & -0.037 \\ \text { Bitter gourd seed } & \beta_{2} & 0.164 \\ \text { T.no of irrigations } & \beta_{3} & 0.168 \\ \text { Pesticide } & \beta_{4} & -0.005 \\ \text { NPK } & \beta_{5} & 0.069 \\ \text { Labor hours } & \beta_{6} & 0.417 \\ \text { Land Preparation hours } & \beta 7 & 0.237 \\ \text { Return to Scale } & & 1.013\end{array}$

This study also examined the average application of inputs from highest (benchmark category) to lowest efficient farms of bitter gourd-capsicum cropping system. Table 6 revealed that in bitter gourd-capsicum cropping system, the application of capsicum seed by the benchmark category is around 320 grams per acre. Apart from (0.401-0.60) category, all the other categories which are although below the benchmark category in terms of output and technical efficiency yet apply a greater amount of capsicum seed per acre. Due to this reason, the variable of capsicum seed has the negative, yet an insignificant impact on bitter gourd-capsicum cropping system (see Table 3 ). The random and uninformed application of capsicum seed has resulted in wastage of farm and financial resources.

The application of bitter gourd seed by the benchmark or highest efficient category of sampled farmers of the study area is around 1911.76 grams per acre. All the categories which are below the benchmark category use the lesser amount of bitter gourd seed per acre, except the second highest (0.801-0.90) category in the sampled data. The result of bitter gourdcapsicum production function analysis also reports the positive significant impact of bitter gourd seed on bitter gourd-capsicum cropping system (see Table 3). Hence, most of the farmers who spread a higher quantity of bitter gourd seed along with improved farm management can maintain the higher farm

Table 6: Inputs application and variation on average from bighest to lowest efficient farms in bitter gourd-capsicum cropping system.

$\begin{array}{llllllll}\text { TE(SFA) } & \begin{array}{l}\text { Capsicum } \\ \text { seed (Grams) }\end{array} & \begin{array}{l}\text { Bitter gourd seed Irrigation (No.) } \\ \text { (Grams) }\end{array} & \text { Pesticide (No.) } & \text { NPK(Kg) } & \text { Labor hour } & \begin{array}{l}\text { Land Prep. } \\ \text { Hour }\end{array} \\ >0.90 & 320.000 & 1911.764 & 36.000 & 25.372 & 491.764 & 5.470 & 74.705 \\ 0.801-0.90 & 330.000 & 2000.000 & 36.812 & 24.875 & 519.531 & 5.500 & 78.229 \\ 0.701-0.80 & 327.619 & 1880.952 & 34.047 & 22.571 & 466.023 & 5.095 & 74.857 \\ 0.601-0.70 & 337.500 & 1875.000 & 36.250 & 24.125 & 378.000 & 4.875 & 67.500 \\ 0.401-0.60 & 305.714 & 1642.857 & 38.285 & 24.714 & 345.357 & 4.714 & 60.857 \\ 0.201-0.40 & 327.142 & 1607.142 & 31.357 & 23.928 & 412.357 & 4.0714 & 56.071 \\ <0.20 & 340.000 & 1500.000 & 36.000 & 25.000 & 481.000 & 5.000 & 60.000\end{array}$

Inputs Variation from Highest to Lowest Efficient Farms in Bitter Gourd-Capsicum Cropping System

\begin{tabular}{|c|c|c|c|c|c|c|c|}
\hline TE(SFA) & $\begin{array}{l}\text { Capsicum } \\
\text { seed (Grams) } \\
\text { Percentage } \Delta\end{array}$ & $\begin{array}{l}\text { Bitter Gourd } \\
\text { Seed (Grams) } \\
\text { Percentage } \Delta\end{array}$ & $\begin{array}{l}\text { No. Irrigation } \\
\text { (No.) Percentage } \\
\Delta\end{array}$ & $\begin{array}{l}\text { Pesticide (No.) } \\
\text { Percentage } \Delta\end{array}$ & $\begin{array}{l}\text { NPK }(\mathrm{Kg}) \\
\text { Percentage } \Delta\end{array}$ & $\begin{array}{l}\text { Labor Hour } \\
\text { Percentage } \Delta\end{array}$ & $\begin{array}{l}\text { Land Prep } \\
\text { Percentage } \Delta\end{array}$ \\
\hline$>0.90$ & - & - & - & - & - & - & - \\
\hline $0.801-0.90$ & -3.125 & -4.615 & -2.257 & 1.960 & -5.646 & -0.537 & -4.71 \\
\hline $0.701-0.80$ & -2.380 & 1.611 & 5.423 & 11.039 & 5.234 & 6.861 & -0.202 \\
\hline $0.601-0.70$ & -5.468 & 1.923 & -0.694 & 4.916 & 23.133 & 10.887 & 9.645 \\
\hline $0.401-0.60$ & 4.464 & 14.065 & -6.349 & 2.594 & 29.771 & 13.824 & 18.537 \\
\hline $0.201-0.40$ & -2.232 & 15.934 & 12.896 & 5.691 & 16.147 & 25.576 & 24.943 \\
\hline$<0.20$ & -6.250 & 21.538 & 0 & 1.468 & 2.189 & 8.602 & 19.685 \\
\hline
\end{tabular}


output in bitter gourd-capsicum cropping system. The average application of number of irrigations by benchmark category is around 36 per acre. The categories of (0.70-0.80) and (0.201-0.40) applied around 5.42 and 12.89 percent higher number of irrigations compared to benchmark category, respectively. On the other hand, categories with ranges (0.801-0.90), (0.601-0.70) and (0.401$0.60)$ apply about $2.25,0.69$ and 6.34 percent lesser number of irrigations relative to benchmark category, respectively.

The application of pesticide spray by benchmark category on average is around 25.37 per acre. The effect of pesticide spray on bitter gourd-capsicum cropping system is negative and insignificant. In case of multiple cropping systems, the study at hand witnesses the insignificant effect of pesticide sprays on both cropping systems (Cotton-melon and bitter gourd-capsicum). The application of pesticide spray in case of multiple cropping systems is complicated as each crop hosts dissimilar pests. Farmers should be more observant regarding the type of pests' attack, especially for those crops that are grown on same space and time. So, vigilant and profound application of pesticide spray is desirable to determine its best possible backing and acting contrarily will result in higher cost of production to the farmers and environmental hazards to the nearby community.

The application of NPK fertilizer by the benchmark category in bitter gourd-capsicum cropping system is on average $419.76 \mathrm{Kg}$ per acre. Except the category of (0.801-0.90), all the other categories utilize the NPK fertilizer in lower quantity relative to the benchmark category.

In the case of labor hours per day, the benchmark category of most efficient farms in sampled data, spends 5.47 hours per acre on average. The labor input in multiple cropping systems is one of the most fundamental inputs. This study identifies that efficient utilization of labor hours in bitter gourd-capsicum cropping system aids to augment the farm output along with other inputs.

In case of land preparation hours, the benchmark category on average used 74.70 hours per acre. The second (0.801-0.90) and third (0.701-0.80) categories in terms of technical efficiency and bitter gourdcapsicum output spend 0.53 and 6.86 more hours for land preparation activities than the benchmark category, respectively. The remaining categories use lesser amount of time for land preparation than benchmark category.

It is needed that farmers recuperate optimal level of bitter gourd-capsicum output through improved farm management technique. Farmers can attain the same level of output through reduction of $21 \%$ of farm inputs or attain optimal level of bitter gourdcapsicum output by using efficient utilization of existing farm inputs. It is essential for farmers to consult the extension services or agricultural research organizations for improvement in existing farming practices.

\section{Bitter gourd-capsicum technical efficiency frequency} distribution

The present study used both SFA and DEA models. Technical efficiency is calculated to find out the technical inefficiency level of bitter gourd-capsicum cropping system. The DEA technique facilitates us to use technical efficiency analysis by using two models, namely constant return to scale and variable return to scale model. The present study shows the result of both DEA models. But for robust efficiency analysis point of view, the study will compare the efficiency scores between SFA and DEA constant return to scale models. Since both (SFA and DEA constant return to scale) models in the present study carried the constant return to scale, it is more plausible and rational to evaluate these models for robust efficiency analysis. The result of the study indicates that technical inefficiency is present in the bitter gourd-capsicum multiple cropping system. As the gamma value from Table 3 is around 0.99 and highly significant. Thus, 99 percent of variation in bitter gourd and capsicum is due to the presence of technical inefficiency in the bitter gourd-capsicum cropping system.

Figure 1 reports that in case of SFA, the technical efficiency of bitter gourd-capsicum cropping system ranges from less than $20 \%$ to greater than $90 \%$. Only $0.67 \%$ of the farms have technical efficiency ranges from less than 20, whereas $9.33 \%$ have between 21-40. The $4.67 \%$ of farms have range of technical efficiency between 41-60, whilst eight farms constituting a total of $5.33 \%$ has the technical efficiency range of $61-70 \%$. The $14 \%$ of farms comes in the range of 71-80 and most of the farms i.e., $32 \%$ and $34 \%$ come in the ranges of $81-90$ and greater than 90 . 
These results put forward that most of the farmers are reasonably efficient. However, further efficient utilization of inputs can result in optimal level of output in bitter gourd-capsicum cropping system. The result obtained from the DEA constant return to scale model is approximately similar as obtained from SFA. Whereas the mean technical efficiency score is precisely the identical.

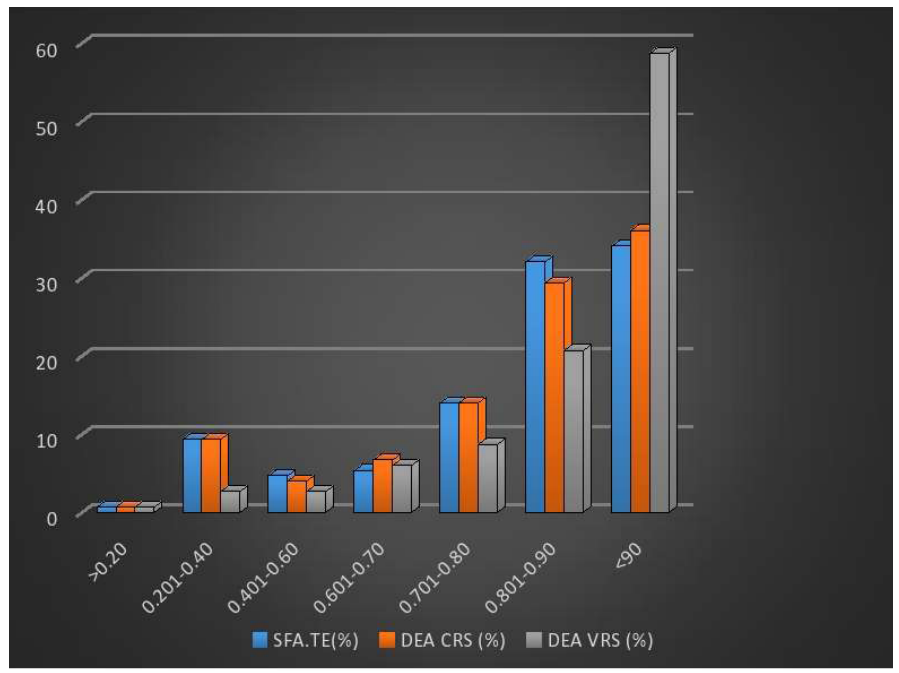

Figure 1: Bitter gourd-capsicum technical efficiency frequency distribution.

The calculation of technical efficiency under the DEA variable return to scale model is mostly ranges between 0.70 to > 90 with a value of around $88 \%$. Only $12 \%$ of farmers fall into other categories. While the mean technical efficiency score is around $88 \%$. The mean technical efficiency of bitter gourdcapsicum farms tunnels by using SFA and DEA constant return to scale is around 0.79. The minimum technical efficiency in SFA, DEA constant return to scale model and variable return to scale model is 0.19 . While the maximum technical efficiency score is 0.98 under SFA and 1 in DEA constant return to scale and variable return to scale model. The technical efficiency scores inveterate that around $21 \%$ of technical inefficiency is present in bitter gourd and capsicum cropping systems. It is necessary for the farmers of the study area to consult with the extension services or research organization regarding the guidance of appropriate level of farm inputs application and also participate in formal and in formal training regarding the adoption of advance farm technologies.

\section{Conclusions and Recommendations}

The study concludes that around $21 \%$ of significant technical inefficiencies present in bitter gourd- capsicum cropping system. The adoption of multiple cropping system under controlled environment (Tunnels) has the pertinent impact on horticultural crop production. The result of current study revealed that cultivation of crops under tunnel even now is relatively advanced farming method and farmers are still under the learning and adoption process. The crop production of the bitter gourd-capsicum cropping system can be enhanced by around $21 \%$ by retaining the same level of inputs. Provided that farmers can apply an appropriate level of farm inputs along with improved farm management practices. Benchmarking analysis bitter gourd-capsicum cropping system validates the unbalanced and excessive use of farm inputs such as seed rate, pesticide sprays, number of irrigations, and NPK. Hence, instead of disregarding available farm resources, farmers should utilize the available farm resources efficiently. Acting contrarily will not enable them to minimize their production cost and maximize the returns on farm output. It is necessary for the farmers to consult with the extension services or research organization for reduction in the number of plant protection sprays and improved yield. During the survey, it was informed by the farmers that neither the research centers are interested to contact the farmers, nor the farmer are willing to contact them. It showed that the government has failed to transfer the advancement in research through extension centers to the farmers. Farmers like to discuss their farming issues with fellow farmers, rather than with people at extension centers that reflects the lack of confidence of the farmers in existing system of extension services.

Balanced use of inputs is one of the main elements to get the best out of multiple cropping systems under tunnels. Farmer should employ the recommend farm inputsinstead of excessiveinputs application.Improved farm management practices are needed to attain the optimal level of farm harvest. Formal and informal training involving advanced farm technologies is essential. It is suggested that farmers should adopt the high-tech technologies after obtaining the proper pieces of training about the use of farm technologies in hand. Consequently, farmers can regain the best out of it. It is important that private and public sector lends the hand together to exploit the existing available factors of production efficiently, to expand the farming productivity and technical efficiency that can result in higher farming productivity of bitter gourd-capsicum cropping system under tunnels. 
Novelty Statement

The aim of this research is to explore the cost efficiency analysis of multiple cropping system under tunnels. Even though many research have been done on multiple cropping system, very few studies have analyzed the cost feasibility of multiple crops under tunnel. Hence, this study is a new addition in respect of viability, cost and returns of growing multiple crops under the tunnels in Pakistan.

\section{Author's Contribution}

Hina Fatima: Presented the main idea, performed literature review, methodology, descriptive, empirical analysis and investigation.

Bushra Yasmin and Lal Khan Almas: Overview, technical input, and supervision on every step of this research.

\section{Confict of interest}

The authors have declared no conflict of interest.

\section{References}

Abedullah, K. Bakhsh and B. Ahmad. 2006. Technical efficiency and its determinants in potato production evidence from Punjab Pakistan. Lahore J. Econ., 11(2): 1-22. https:// doi.org/10.35536/lje.2006.v11.i2.a1

Abedullah, S., Kouser and M. Khalid. 2007. Analysis of technical efficiency of rice in Punjab (Pakistan) Implication for future Investment Strategies. Pak. Econ. Soc. Rev., 45(2): 231-244.

Ahmad,M. and A. Ahmad.1998. An analysis of the sources of wheat output growth in the barani area of the Punjab. Pak. Dev. Rev. (Autumn), pp. 231-249. https://doi.org/10.30541/ v37i3pp.231-249

Ahmad, M., G.C. Mustafa and M. Iqbal. 2002. Wheat Productivity, efficiency and sustainability: A stochastic production frontier analysis. Pak. Dev. Rev., 41: 643-663. https:// doi.org/10.30541/v41i4IIpp.643-663

Aigner, D.J. and P. Schmidt. 1980. Specification and estimation of frontier production, profit and cost functions. Ann. Appl. Econ. Suppl. J. Econ. North Holland.

Alene, D.A. and M. Zeller. 2005. Technology adoption and farmer efficiency in multiple crops production in Eastern Ethiopia: A comparison of parametric and non-parametric distance functions. Agric. Econ. Rev. 6(1): 5-17.

Ali, G., A.M. Dawood, S.A.M. Dawood, J. Abbasullah, J.M. Fayaz, U. Irfan and K.Z. Muhammad. 2013. Technical efficiency of sugar cane production in district dera Ismail Khan. Sarhad J. Agric., 29(4): 585-590.

Ali, M., and J.C. Flinn. 1989. Profit efficiency among basmati rice producers in Pakistan, Punjab. Am. J. Agric. Econ., 71: 303-310. https://doi.org/10.2307/1241587

Amos, T., T.D.O. Chikwendu and J.N. Nmadu.2004. Productivity, technical efficiency and cropping patterns in the Savanna zone of Nigeria. J. Food, Agric. Environ., 2(2): 173-176.

Askal, A.A., 2010. Technical efficiency of farmers in Ethiopia: A stochastic production frontier approach. Masters Thesis. Paper 210 http:// thekeep.eiu.edu/these/210

Banker, R.D., A. Charnes and W.W. Cooper. 1984. Some models for estimating technical and scale inefficiencies in data envelopment analysis. J. Manage. Sci., 30: 1078-1092. https://doi. org/10.1287/mnsc.30.9.1078

Battese, G.E. and T.J. Collie. 1995. A model for Technical inefficiency effects in a stochastic frontier production function for panel data. Empirical. Econ., 20: 325-332. https://doi. org/10.1007/BF01205442

Battese, G.E. and T.J. Coelli. 1996. Identification of factors which influence the technical inefficiency of Indian farmers. Aust. J. Agric. Econ., 40: 103-128. https://doi. org/10.1111/j.1467-8489.1996.tb00558.x

Battese, G.E. and T.J. Coelli. 1988. Prediction of firm-level technical efficiencies with a generalized frontier production function and panel data. J. Econ., 38: 387-399. https://doi. org/10.1016/0304-4076(88)90053-X

Battese, G.E. and G.S. Corra. 1977. Estimation of a production frontier model: with application to the pastoral zone of Eastern Australia. Aust. J. Agric. Econ., 21: 169-179. https://doi. org/10.1111/j.1467-8489.1977.tb00204.x

Beshir, H.H., 2011. Performance of mixed crop-livestock production system: The data envelopment approach. Livest. Res. Rural Dev., pp. 23.

Bravo-Ureta, B.E. and A.E. Pinheiro. 1993. Efficiency analysis of developing country agriculture: A review of the frontier function 
literature. Agric. Res. Econ. Rev., 22(1): 88-101. https://doi.org/10.1017/S1068280500000320

Coelli, T.J., 1996. A guide to DEAP version 2.1: A data envelopment analysis (Computer) Program, CEPA Working Paper No. 8/96, ISBN 186389 4969, Department of Econometrics, University of New England

Coelli, T.J., R. Pardse and G.E. Battese. 1998. An introduction to efficiency and productivity analysis. Kluwer Academic, Boston. https://doi. org/10.1007/978-1-4615-5493-6

Coelli, T.J., 1996. A Guide to FRONTIER Version 4.1: A computer program for stochastic frontier production and cost function estimation, CEPA Working Papers, No. 7/96, ISBN 186389 4950, Department of Econometrics, University of New England, Amidala

Coelli, T.J., 1995. Recent developments in frontier modelling and efficiency measurement. Aust. J. Agric. Econ., 39: 219-245. https://doi. org/10.1111/j.1467-8489.1995.tb00552.x

Datar, G. and X.V. Del Carpio. 2009. Are irrigation rehabilitation projects good for poor farmers in Peru? Policy Research working paper; no. WPS 5154, Impact Evaluation series; no. IE 42. World Bank. https://doi.org/10.1596/18139450-5154

Farrell, M.J. and M. Fieldhouse. 1962. Estimating efficient production functions under increasing returns to scale. J. R. Stat. Soc. Ser. A., 125: 252267. https://doi.org/10.2307/2982329

Farrell, M.J., 1957. The measurement of production efficiency. J. R. Stat. Soc., 120: 257-281. https:// doi.org/10.2307/2343100

Fatima, H. and K. Azeem. 2015. Influence of wheat varieties on technical efficiency and production of wheat crop in Pakistan (In selected area of Punjab). Sarhad J. Agric., 31(2): 114-122. https://doi.org/10.17582/journal. sja/2015/31.2.114.122

Forsund, F.R., C.A.K. Lovell and P. Schmidt. 1980. A survey of frontier production functions and of their relationship to efficiency measurement. J. Econ., 13: 5-25. https://doi.org/10.1016/03044076(80)90040-8

GoP, 2010. Economic Survey of Pakistan, Ministry of Finance Islamabad.

Greene, W.H., 2007. The econometric approach to efficiencyanalysis:The measurementofefficiency, H. Fried, K. Lovell and S. Schmidt, eds., Oxford University Press. https://doi.org/10.1093/ acprof:oso/9780195183528.003.0002

Hasnain, N.M., H.E. Muhammad and I.K. Mohummad. 2015. Technical efficiency of boro rice production in Meherpur district of Bangladesh: A stochastic frontier Approach. Am. J. Agric. For., 3(2): 31-37. https://doi. org/10.11648/j.ajaf.20150302.14

Hassan, S. and B. Ahmad.2005. Technical efficiency of wheat farmers in mixed farming system of the Punjab, Pakistan. Int. J. Agric. Biol., 7(3): 431-435

Hussain, A.A., M. Saboor, A. Khan, A.Q. Mohsin, F. Hassan and M.Z. Anwar. 2012. Technical efficiency of wheat production in PunjabPakistan: A cropping zone wise analysis. Pak. J. Life Soc. Sci., 10(2): 130-138.

Hussain, S.S., 1995. Analysis of allocative efficiency in Northern Pakistan. Pak. Dev. Rev., 34(4): 1167-1180. https://doi.org/10.30541/ v34i4IIIpp.1167-1180

Jondrow, J., C.A.K. Lovell, I.S. Materov and P. Schmidt. 1982. On the estimation of technical inefficiency in the stochastic frontier production function model. J. Econ., 19: 233-238. https:// doi.org/10.1016/0304-4076(82)90004-5

Kalirajan, K.P. and J.C. Flinn. 1983. The Measurement of farm specific technical efficiency. J. Appl. Econ., 2: 167-180.

Kalirajan, K.P., 1991. The Importance of efficient use in the adoption of technology: A micro panel data analysis. J. Prod. Anal., 2(2): 113126. https://doi.org/10.1007/BF00156342

Khan, H. and F. Ali. 2013. Measurement of productive efficiency of tomato growers in Peshawar, Pakistan, Agric. Econ., CZECH, 59(8): 381-388. https://doi. org/10.17221/107/2012-AGRICECON

Kolawole, O., 2009. Technical efficiency of farmers under different multi-cropping systems in Nigeria. Trop. Subtrop. Agro Ecosyst., 10: 117120.

Lee,L.F. and W.G.Tyler. 1978. A stochastic frontier production function and average efficiency: An empirical analysis. J. Econ., 7: 385-390. https:// doi.org/10.1016/0304-4076(78)90061-1

Lovell, C.A.K. and S.S. Schmidt. 1993. The measurement of productive efficiency: Techniques and applications, Oxford University Press. pp. 3-67.

Manyong, V.M., D.A. Arega and G. James. 2006. The production efficiency of intercropping 
annual and perennial crops in southern Ethiopia: A comparison of distance functions and production frontiers. J. Agric. Syst., 91(1-2): 51-70. https://doi.org/10.1016/j. agsy.2006.01.007

Meeusen, W. and J. Van den Broeck. 1977. Efficiency estimation from Cobb-Douglas production functions with composed error. Int. J. Econ. Rev., 18: 435-444. https://doi. org/10.2307/2525757

Mkhabela, T., 2005. Technical Efficiency in a vegetable based mixed-cropping sector in Tugela Ferry, Msinga District, and Kwazulu Natal, South Africa. Agric. Econ. Res. Policy S. Afr., 44(2): 187-204. https://doi.org/10.1080/0 3031853.2005.9523709

Neff, D.L., P. Garcia and C.H. Nelson. 1993. Technicalefficiency:Acomparisonofproduction frontier methods. J. Agric. Econ., 44: 479-489. https://doi.org/10.1111/j.1477-9552.1993. tb00289.x

Nkonya, E., J. Pender, C. Kaizzi, E. Kato and S. Mugarura. 2005. Policy option for increasing crop productivity and reducing soil nutrient depletion and poverty in Uganda. IFPRI ETP discussion paper 134. Washington, DC, International Food Policy Research Institute.

Obwona, M., 2000. Determinants of technical efficiency among small and medium scale farmers in Uganda: A case of tobacco growers. Final report presented at the AERC Biannual Research Workshop, Nairobi, Kenya. 27 May-2 June.

Ogundele, O.O., 2003. Technology differentials and resource use efficiency in rice production in Kaduna state, Nigeria. Unpublished $\mathrm{PhD}$ thesis, Department of Agricultural Economics, University of Ibadan.

Okoboi, G. 2010. Improved inputs use and productivity in Uganda's maize sub-sector, Research Series 101714, Economic Policy Research Centre (EPRC).

Pitt, M.M. and L.O.F. Lee.1981. The measurement and sources of technical inefficiency in the Indonesian weaving industry. J. Dev. Econ., 9: 43-64. https://doi.org/10.1016/03043878(81)90004-3

Saddozai, K.N. A. Saboor, A. Khan, A.M.D. Jan and G. Ali. 2013. Analyzing the impact of farmer field school on technical efficiency of cotton growers in Southern Districts of PunjabPakistan. Sarhad J. Agric., 29(2): 291-298.

Sadiq, G., H.U. Zahoor, A. Farman, M. Khalid, S. Musawar and K. Inamullah. 2009. Technical efficiency of maize farmers in various ecological zones of AJK. Sarhad J. Agric., 25(4): 606-610.

Saeed, M. and A.N. Saeed. 2007. Measurement of economic efficiency in agriculture of Peshawar district. Sarhad J. Agric., 23(1): 197-206.

Schmidt, P. and R.C. Sickles. 1984. Production frontiers and panel data. J. Bus. Econ. Stat., 2: 367-374. https://doi.org/10.1080/07350015.1 984.10509410

Shumet,A., 2011. Analysis of technical efficiency of crop producing smallholder farmers in Tigray, Ethiopia. MPRA Paper No. 40461, Available online at http://mpra.ub.uni-muenchen. $\mathrm{de} / 40461 /$

Suresh, A. and T.R.K. Reddy. 2006. Resourceuse efficiency of paddy cultivation in Peechi command area of Thrissur district of Kerala. Econ. Anal. Agric. Econ. Res. Rev., 19: 159171.

Tella, A.T., 2006. Technical efficiency of cassava production in Afijio local government area of Oyo state. Unpublished MSc thesis, Department of Agricultural Economics, University of Ibadan. 